\title{
Insulin pump
}

National Diabetes Information Clearinghouse (NDIC)

\section{Definitions}

Bolus

Defined by National Diabetes Information Clearinghouse (NDIC)

Blood glucose

Defined by National Diabetes Information Clearinghouse (NDIC)

Insulin

Defined by National Diabetes Information Clearinghouse (NDIC)

\section{Source}

National Diabetes Information Clearinghouse (U.S.). (2009). The diabetes dictionary. [Bethesda, Md.]: U.S. Dept. of Health and Human Services, National Institutes of Health, National Institute of Diabetes and Digestive and Kidney Diseases, National Diabetes Information Clearinghouse.

An insulin-delivering device about the size of a deck of cards that can be worn on a belt or kept in a pocket. An insulin pump connects to narrow, flexible plastic tubing that ends with a needle inserted just under the skin. Users set the pump to give a steady trickle or basal amount of insulin continuously throughout the day. Pumps release bolus doses of insulin at meals and at times when blood glucose is too high, based on doses set by the user. 